\title{
Conhecimento (socio)linguístico, livro didático e ensino de português
}

\author{
The (socio)linguistic knowledge, the \\ didactic book and the Portuguese \\ teaching
}

Cristina dos Santos Carvalho ${ }^{1}$

Resumo: Norteado por pressupostos teóricos da Sociolinguística Variacionista (BRIGHT, 1974; LABOV, 1983, 1995; WEINREICH; LABOV; HERZOG, 2006 [1968]) e da chamada Sociolinguística Educacional (BORTONIRICARDO, 2004, 2005; VIEIRA, 2013, MARTINS; VIEIRA; TAVARES, 2014, dentre outros), este trabalho pretende examinar imprecisões conceituais e inadequações procedimentais concernentes ao tratamento da variação linguística no livro didático de português. Busca ainda fazer uma reflexão sobre os conhecimentos (socio) linguísticos necessários ao professor de língua materna para, na sua prática pedagógica, lidar com essas imprecisões/inadequações. Para tanto, toma como amostra quatro coleções de língua portuguesa do Ensino Fundamental (duas do quarto ao quinto ano e duas do sexto ao nono ano), aprovadas em diferentes anos do PNLD (Programa Nacional do Livro e do Material Didático), e se baseia também nos resultados de Carvalho (2012) e Carvalho e Oliveira (2016).

Palavras-chave: Variação linguística. Livro didático de português. Conhecimento (socio)linguístico. Ensino de língua portuguesa.

Abstract: Based on theoretical assumptions from the Variationist Sociolinguistics (BRIGHT, 1974; LABOV, 1983, 1995; WEINREICH; LABOV; HERZOG, 2006 [1968]) and the so-called Educational Sociolinguistics (BORTONIRICARDO, 2004, 2005; VIEIRA, 2013; MARTINS; VIEIRA; TAVARES, 2014, among others), this paper aims to examine conceptual inaccuracies and procedural inadequacies concerning the treatment of linguistic variation in the didactic book of Portuguese. It is also intended to reflect on the (socio) linguistic knowledge required by the teacher in order to deal with these inaccuracies / inadequacies in his/her pedagogical practice. Then, it takes as a sample four Portuguese collections of Elementary School (two from the fourth to the fifth year and two from the sixth to the ninth year), approved in different years of PNLD (National Program of Didactic Book and Material), and it is also based on the results of Carvalho (2012) and Carvalho e Oliveira (2016).

Keywords: Linguistic variation. Didactic book of Portuguese. (Socio)linguistic knowledge. Teaching of Portuguese.

\section{Introdução}

No que diz respeito aos estudos linguísticos, a discussão acerca da variação linguística e ensino de língua materna tem sido realizada a partir do que tem sido denominado de sociolinguística educacional

${ }_{1}^{1}$ Professora Titular da Universidade do Estado da Bahia (UNEB) e docente permanente do Programa de Pós-Graduação em Estudo de Linguagens (PPGEL). E-mail: crystycarvalho@yahoo.com.br. 
(BORTONI-RICARDO, 2004, 2005) ou reeducação sociolinguística (BAGNO, 2007) ou pedagogia da variação linguística (BAGNO, 2007; ZILLES; FARACO, 2015; CYRANKA, 2015). Independentemente do rótulo atribuído, tal discussão não tem se limitado apenas à consideração de questões teóricas, mas também à análise de situações pedagógicas e materiais didáticos e à sugestão de propostas de intervenções em sala de aula.

Todavia, os entraves ainda permanecem no que diz respeito à abordagem da variação linguística em materiais pedagógicos e, mais especificamente, em livros didáticos de português. Em Carvalho (2012), essa questão já havia sido caracterizada como um desafio para o professor de língua materna, o que também é ressaltado por Martins, Vieira e Tavares (2014):

\begin{abstract}
Um dos maiores desafios das aulas de Português diz respeito, sem dúvida, ao tratamento da variação linguística e, fundamentalmente, aos saberes gramaticais permeados por diferentes normas linguísticas - que devem estar presentes na escola. Com o amplo acesso dos brasileiros aos bancos escolares, especialmente no primeiro nível do ensino fundamental, a multifacetada realidade brasileira, em todas as suas expressões socioculturais, reflete-se na produtiva e saudável convivência de diversas variedades linguísticas na vida escolar. Conhecer essa realidade plural ocupou e ocupa a agenda dos estudos sociolinguísticos brasileiros [...]. (MARTINS; VIEIRA; TAVARES, 2014. p. 9)
\end{abstract}

Além dessa agenda de trabalhos sociolinguísticos, já há uma gama de orientações oficiais, expressas, por exemplo, nos Parâmetros Curriculares Nacionais (PCN), no Programa Nacional do Livro e do Material Didático (PNLD)2, na Base Nacional Comum Curricular (BNCC), que fornecem um embasamento teórico-metodológico para a alocação do fenômeno da variação linguística em sala de aula. Sendo assim, por um lado, não se entende por que os percalços insistem em continuar e, por outro, entende-se por que a reflexão que será aqui apresentada continua tão necessária e atual.

Se o professor de língua materna se depara com desafios, não é diferente com os autores dos livros didáticos, cuja tarefa é bastante árdua: "a utilização de uma linguagem acessível ao público-alvo, a heterogeneidade de fontes de informação e o equilíbrio entre as partes da obra são apenas alguns exemplos dos desafios enfrentados por quem elabora livros didáticos" (LIMA, 2014, p. 116).

No cenário do ensino de português, em relação aos livros didáticos, como mencionado em Carvalho (2012), vislumbra-se, pelo menos, um alento: "uma constatação positiva é que já existe uma preocupação, por parte dos autores, em inserir aspectos relacionados à variação entre os conteúdos das suas obras" (CARVALHO, 2012, p. 1146). Contudo, não basta apenas citar tais aspectos, uma vez que, conforme bem lembra Dionísio (2002), mencionar o fenômeno de variação, a existência de variedades linguísticas nem sempre é sinônimo de respeito. Para ela, "parece que os autores do LDP [livro didático de português] estão ainda 'acertando o passo' no estudo das VL [variedades linguísticas]" (DIONÍSIO, 2002, p. 87). E dezesseis anos depois, ainda não o encontraram completamente.

Alguns livros didáticos de português aprovados pelo PNLD, apesar das diretrizes do Programa, ainda apresentam inconsistências conceituais e metodológicas nos diferentes eixos de ensino (leitura, produção de textos, oralidade e conhecimentos linguísticos). Nesse caso, é preciso que o professor de

\footnotetext{
2 O PNLD ganhou nova nomenclatura motivada pelo Decreto no 9.099, de 18 de julho de 2017, que "unificou as ações de aquisição e distribuição de livros didáticos e literários, anteriormente contempladas pelo Programa Nacional do Livro Didático (PNLD) e pelo Programa Nacional Biblioteca da Escola (PNBE)" (http://portal.mec.gov.br/component/content/article?id=12391:pnld).
} 
língua materna atue como mediador, propondo as intervenções adequadas para não reproduzir e, por conseguinte, perpetuar tais inconsistências. No entanto, para fazer as devidas intervenções, esse profissional tem que ter uma sólida formação (socio)linguística.

Levando-se em conta as considerações supracitadas, este trabalho pretende analisar imprecisões conceituais e inadequações procedimentais relacionadas à abordagem da variação linguística no livro didático de português. Ademais, pretende-se refletir aqui sobre os conhecimentos (socio)linguísticos necessários ao professor de língua materna para, na sua prática pedagógica, lidar com essas imprecisões/inadequações. A reflexão a ser empreendida orienta-se pelos postulados teóricos da Sociolinguística Variacionista (BRIGHT, 1974; LABOV, 1983, 1995; WEINREICH; LABOV; HERZOG, 2006 [1968]) e da chamada Sociolinguística Educacional (BORTONI-RICARDO, 2004, 2005; VIEIRA, 2013; MARTINS; VIEIRA; TAVARES, 2014, dentre outros) e parte do exame de quatro coleções de língua portuguesa do Ensino Fundamental (duas do quarto ao quinto ano e duas do sexto ao nono ano) e dos resultados de Carvalho (2012) e Carvalho e Oliveira (2016).

O artigo está estruturado em duas partes. Na primeira, destacam-se, de modo conciso, postulados da Sociolinguística Variacionista, as suas implicações para a educação em língua materna pelo viés da Sociolinguística Educacional e a relevância do conhecimento desses postulados pelo professor de língua materna para a sua praxis pedagógica no que concerne ao ensino da variação linguística. $\mathrm{Na}$ segunda, enfoca-se como o fenômeno da variação linguística é contemplado em livros didáticos de português aprovados pelo PNLD, quais são as imprecisões conceituais e inadequações procedimentais mais recorrentes nesses livros e os conhecimentos (socio)linguísticos que devem ser mobilizados pelo professor para identificar e dirimir essas inconsistências teórico-metodológicas. Por fim, apresentam-se as considerações finais em relação à discussão feita.

\section{Dos conhecimentos dos postulados da Sociolinguística para a sala de aula: o ensino da variação}

Desde o advento da Sociolinguística na década de 1960, tem-se delimitado como objeto de estudo dessa área da línguística, na vertente variacionista, a diversidade ou heterogeneidade linguística (BRIGHT, 1974), que se manifesta, nas línguas humanas, por intermédio dos processos de variação e mudança. Ainda em relação ao objeto de estudo, conforme se vê em Labov $(1983,1995)$ e Weinreich, Labov e Herzog, 2006 [1968], tem-se enfatizado a sistematicidade da variação linguística, o que tem implicado a assunção de outros postulados fundamentais aos estudos sociolinguísticos, a saber: a variação é uma propriedade universal, contínua e inerente às línguas; sendo sistemática, a variação pode ser descrita e analisada cientificamente, partindo do princípio de que ela é motivada por fatores linguísticos ou estruturais (fonológicos, morfológicos, sintáticos, semânticos) ou extralinguísticos (grau de escolaridade, sexo/gênero, faixa etária, rede social etc); todas as variedades de uma língua são igualmente complexas já que atendem às necessidades sociocomunicativas da comunidade que as utiliza; existe uma relação entre variação e mudança no sentido de que nem toda variação implica mudança mas toda mudança pressupõe variação.

Passados mais de cinquenta anos desde o surgimento da Sociolinguística, são inegáveis a importância e as implicações desses postulados para a educação em língua materna. Sobre essa questão, 
Martins, Vieira e Tavares (2014), a partir do conhecimento provido pelos pressupostos dos estudos sociolinguísticos, sintetizam as contribuições gerais desses estudos ao ensino em três quesitos: (i) definição de conceitos básicos - as concepções de norma (culta, padrão), as diferenças entre fala e escrita, a distinção entre norma, registro e modalidade - para o tratamento da variação linguística na prática escolar; (ii) reconhecimento de uma norma culta plural: a variedade de usos na prática de leitura e produção de textos orais e escritos; (iii) reconhecimento das semelhanças entre variedades cultas e populares.

E é do reconhecimento da relevância dos postulados sociolinguísticos para o ensino que, nos anos 2000, surge o que tem sido designado por Bortoni-Ricardo $(2004,2005)$ de Sociolinguística Educacional, rótulo que, de forma genérica, abrange "todas as propostas e pesquisas sociolinguísticas que tenham por objetivo contribuir para o aperfeiçoamento do processo educacional, principalmente na área do ensino de língua materna (BORTONI-RICARDO, 2005, p. 128). Em outras palavras, para a autora, a tarefa da Sociolinguística Educacional vai além da descrição da variação e divulgação dos resultados, devendo "contribuir para o desenvolvimento de uma pedagogia sensível às diferenças sociolinguísticas e culturais dos alunos", o que "requer uma mudança de postura da escola - de professores e alunos - e da sociedade em geral" (BORTONI-RICARDO, 2005, p. 130). Nesse sentido, é importante que a escola e a sociedade, além de reconhecerem a diversidade linguística, combatam o preconceito linguístico.

Assim posto, a Sociolinguística Educacional, na sua agenda de trabalho, propõe ao docente, entre outras, a seguinte orientação teórico-metodológica:

[...] que se leve para as salas de aula a discussão sobre a variação linguística, orientando os alunos a reconhecerem as diferenças dialetais e, mais importante, a compreenderem que essas diferenças são normais, legítimas e que devem ser consideradas na seleção das estruturas a serem utilizadas a depender das condições de produção [...]. (CYRANKA, 2016, p. 169).

A partir da orientação supracitada, infere-se o quanto é essencial a mudança na postura do professor de língua materna em relação ao trabalho com a variação linguística. Desse modo, é crucial que o professor desempenhe um papel mais ativo na condução do seu trabalho, tanto no planejamento como na execução de suas aulas. A esse respeito, Bagno (1999) alerta para o fato de que a mudança de atitude do professor deve ocorrer sob as perspectivas teórica e prática. Assim, do ponto de vista teórico, é preciso que o professor reflita sobre os conteúdos a serem ministrados em vez de apenas repeti-los; do ponto de vista prático, o professor deve "PRODUZIR seu próprio conhecimento de gramática, transformando-se num pesquisador em tempo integral, num orientador de pesquisas a serem empreendidas em sala de aula, junto com seus alunos" (BAGNO, 1999, p. 117). Ademais, esse profissional também deve ter uma atitude crítica em relação aos materiais didáticos que utiliza para identificar possíveis incoerências, preconceitos, conservadorismo.

As mudanças na postura do professor podem ser associadas ao que Bagno (2007) denomina de

\section{reeducação sociolinguística:}

[...] estamos falando de uma reeducação, de uma educação nova, de uma reorganização dos saberes linguísticos que não tem nada a ver com "correção" [...] ao contrário, a reeducação sociolinguística tem que partir daquilo que a pessoa já sabe e sabe bem: falar a sua língua materna com desenvoltura e eficiência. (BAGNO, 2007, p. 83) 
Para a implementação de uma (re)educação sociolinguística eficiente, é necessária uma mudança de atitude não só do professor de português mas de todos os outros profissionais envolvidos no processo educacional. Tal (re)educação tem que estar prevista no planejamento macro das ações de ensino de uma escola, ou seja, seu no Projeto Pedagógico, que, nos termos de Cafiero (2010, p. 89), constitui "um espaço privilegiado para organização [e articulação de todas as disciplinas] que elimina[m] a fragmentação do ensino".

Ainda no que diz respeito ao professor de português, para que ele possa estar mais consciente da necessidade de uma práxis voltada para a (re)educação sociolinguística, é indispensável o acesso a uma formação (socio)linguística desde a sua graduação. Sabe-se que nem sempre isso acontece e, quando acontece, às vezes, a formação é deficitária. Sobre essa questão, Bagno e Rangel (2005) afirmam que:

\begin{abstract}
Muitos são os estudantes que se graduam em Letras sem jamais terem ouvido falar, em sua formação, de pragmática linguística, de análise do discurso, de linguística textual, de análise da conversação, de letramento, de gramaticalização, de gêneros textuais e de outras áreas de investigação que, paradoxalmente, se encontram em plena ebulição nos centros de pesquisa das grandes universidades brasileiras. Outros campos de estudo, como a sociolinguística e a semântica, que chegam a constituir, em alguns casos, disciplinas com esses mesmos nomes, são abordados de forma esquemática e pouco instigadora. Todas essas áreas de estudo, no entanto, são de fundamental importância para a formação de docentes capazes de promover a plena educação linguística de seus alunos (BAGNO; RANGEL, 2005, p.86).
\end{abstract}

Embora treze anos tenham se passado, infelizmente, a afirmação dos autores, por um lado, continua ainda bastante atual. Por outro lado, essa não é a regra geral de todos os cursos de Letras do país: já se podem entrever mudanças nas estruturas curriculares de alguns desses cursos, como é o caso daqueles oferecidos pela Universidade do Estado da Bahia, que já incluem nas suas propostas curriculares disciplinas como Diversidade Linguística, Estudos Linguísticos Contemporâneos, Texto e Discurso, entre outras. Ademais, em qualquer uma dessas situações, não se pode perder de vista que é possível complementar/fortalecer a formação da graduação com cursos de pós-graduação e qualificação docente, o que significa dizer que o profissional em sala de aula não pode parar de se qualificar. Em suma, o que se quer acentuar aqui é a importância da formação (socio)linguística inicial e continuada para o professor de português.

Na próxima seção, ressalta-se essa necessidade de articulação entre conhecimento científico e ensino em sala de aula. Mais especificamente, discute-se o tratamento do fenômeno da variação linguística no livro didático de português, destacando-se imprecisões conceituais e inadequações procedimentais mais recorrentes e os conhecimentos (socio)linguísticos necessários ao professor de português para fazer as devidas intervenções e, assim, dirimir tais imprecisões/inadequações.

\title{
Variação linguística em coleções de língua portuguesa do Ensino Fundamental: algumas inconsistências teórico-metodológicas
}

Para a abordagem da variação linguística no livro didático, como já mencionado, consideram-se os achados de Carvalho (2012) e Carvalho e Oliveira (2016) e examinam-se quatro coleções de língua 
portuguesa do Ensino Fundamental (EF): duas do quarto ao quinto ano (EF1) e duas do sexto ao nono ano (EF2), conforme demonstra o quadro 1. Os critérios para a seleção dessas coleções foram os seguintes: terem sido aprovadas no PNLD $(2013,2014,2017)$ e serem adotadas em escolas públicas brasileiras. 
Quadro 1: Caracterização das coleções

\begin{tabular}{|c|c|c|c|c|}
\hline Título & Autor(es) & Volume & Tipo & $\begin{array}{l}\text { Ano de aprovação no } \\
\text { PNLD }\end{array}$ \\
\hline $\begin{array}{l}\text { Aprender Juntos - } \\
\text { Língua } \\
\text { Portuguesa }\end{array}$ & Adson Vasconcelos & $4-5$ & 1 & 2013 \\
\hline $\begin{array}{l}\text { Português, Escrita, } \\
\text { Leitura e Oralidade }\end{array}$ & $\begin{array}{l}\text { Débora Vaz, Elody Nunes } \\
\text { Morais e Rosângela Veliago }\end{array}$ & $4-5$ & 1 & 2013 \\
\hline $\begin{array}{l}\text { Para Viver Juntos } \\
\text { Português }\end{array}$ & $\begin{array}{l}\text { Cibele Lopresti Costa, Greta } \\
\text { Marcheti, Jairo J. Batista Soares, } \\
\text { Márcia Takeuchi, Eliane Gouvêa } \\
\text { Lousada, Manuela Prado, Ana Elisa } \\
\text { de Arruda Penteado, Heidi Strecker, } \\
\text { Maria Virgínia Scopacasa, Mirella L. } \\
\text { Cleto }\end{array}$ & $6-9$ & 2 & 2014 \\
\hline $\begin{array}{l}\text { Tecendo linguagens } \\
\text { - Língua Portuguesa }\end{array}$ & $\begin{array}{l}\text { Tania Amaral Oliveira, Elizabeth } \\
\text { Gavioli de Oliveira Silva, Cícero de } \\
\text { Oliveira Silva, Lucy Aparecida Melo } \\
\text { Araújo. }\end{array}$ & $6-9$ & 1 & 2017 \\
\hline
\end{tabular}

Fonte: Elaborado pela autora.

Note-se que, das quatro coleções, três apresentam apenas material impresso (Livro do Aluno e Manual do Professor), sendo caracterizadas, no PNLD, como do tipo 1 e uma contém ainda o material multimídia ou Objetos Educacionais Digitais (OED), classificada como do tipo $2^{3}$. Os seus princípios organizadores, em relação à distribuição de unidades e capítulos, variam entre: tema e projeto (Aprender Juntos - Língua Portuguesa); gênero textual e projeto (Português, Escrita, Leitura e Oralidade e Para Viver Juntos Português); tema, gênero textual e projeto (Tecendo linguagens - Língua Portuguesa).

Atendendo a um dos critérios do PNLD específicos para a língua portuguesa, todas as coleções estão organizadas em função dos quatro eixos de ensino: leitura, produção de texto escrito, oralidade e conhecimentos linguísticos. Outro requisito que é respeitado tem a ver com a consideração, nos conteúdos e atividades, da variação linguística e, mais especificamente, das variedades regionais e sociais do português. $O$ não atendimento a essas duas exigências implicaria a eliminação das coleções. Correlacionando-se os dois critérios, nas obras didáticas analisadas, a variação linguística tende a ser mais abordada, de forma sistematizada, no eixo de conhecimentos linguísticos ou oralidade e pode haver alguma referência a esse fenômeno nos eixos de leitura e produção de textos.

Os conteúdos sistematizados concernentes à diversidade linguística nem sempre aparecem em todos os volumes de uma mesma coleção. 0 quadro 2 mostra a distribuição desses conteúdos nas coleções do $4^{\circ}$ e $5^{\circ}$ anos. Observe-se que essas duas coleções se encontram em distribuição complementar: uma - Aprender Juntos - Língua Portuguesa - só apresenta o estudo da variação linguística no volume 4 e outra - Português, Escrita, Leitura e Oralidade -, no volume 5. Não há explicação por parte dos autores para justificar a inclusão de um conteúdo em um volume e a exclusão em outro. Também não se consegue depreender qual o critério para a adoção desse procedimento.

\footnotetext{
${ }^{3}$ Como já mencionado em Carvalho e Oliveira (2016), a possibilidade de as editoras incluírem os chamados Objetos Educacionais Digitais (OED) nas obras inscritas foi proposta no Edital 06/2011, para o PNLD 2014.
} 
Quadro 2: Conteúdos sistematizados referentes à diversidade linguística nas coleções do 40 e $5^{\circ}$ anos

\begin{tabular}{|l|l|l|}
\hline \multirow{2}{*}{ Coleção } & Conteúdos \\
\cline { 2 - 3 } $\begin{array}{l}\text { Aprender Juntos } \\
\text { Língua Portuguesa }\end{array}$ & & $\begin{array}{l}\text { Volume 5 } \\
\text { Português ou brasileiro? } \\
\text { (p. 66-67) } \\
\text { Marcas da oralidade no texto } \\
\text { escrito } \\
\text { (p. 196-197) } \\
\text { Variedades linguísticas } \\
\text { (p. 242-243). }\end{array}$ \\
\hline $\begin{array}{l}\text { Português, Escrita, } \\
\text { Leitura e Oralidade }\end{array}$ & $\begin{array}{l}\text { Diferenças entre fala e escrita } \\
\text { (p. 68, at.1; p. 156) } \\
\text { Diferenças lexicais entre as variedades } \\
\text { brasileira e europeia do português } \\
\text { (p. 157-159). }\end{array}$ & \\
\hline
\end{tabular}

Fonte: Carvalho (2012, p. 1155).

Outra questão observada é que existe uma tendência a haver uma discrepância dos conteúdos sobre variação linguística nos volumes das coleções do $6^{\circ}$ ao $9^{\circ}$ ano. Geralmente, dá-se uma ênfase à abordagem desses conteúdos no $6^{\circ}$ ano e há, nos anos subsequentes, uma eliminação ou uma redução drástica deles, conforme expresso no quadro 3.

Quadro 3: Conteúdos sistematizados referentes à diversidade linguística linguística nas coleções do $6^{\circ}$ ao $9^{\circ}$ anos

\begin{tabular}{|l|l|l|}
\hline Coleção & Conteúdos & Volume \\
\hline \multirow{3}{*}{$\begin{array}{l}\text { Para Viver Juntos } \\
\text { Português }\end{array}$} & Variação linguística: variedades regionais & v. 6 (p. 60-61) \\
& A variação linguística e a caracterização de personagens & v. 6 (p. 62-63) \\
& Variação linguística: variedades sociais e situacionais & v. 6 (p. 72-76) \\
& Linguagem e adequação à situação discursiva & v. 6 (p.77) \\
\hline \multirow{3}{*}{$\begin{array}{l}\text { Tecendo linguagens } \\
\text { Língua Portuguesa }\end{array}$} & Variedade linguística & v.6 (p.74) \\
& Níveis de linguagem: formal e informal & v.6 (p.74-75) \\
& Marcas de conversação & v.6 (p.111) \\
& Linguagem oral e escrita & v.6 (p.161-162) \\
& Marcas de oralidade & v.6 (p. 220) \\
& Variação linguística & v.6 (p. 222) \\
\cline { 2 - 3 } & Marcas da oralidade & v.7 (p. 56-57) \\
& Marcas de oralidade no texto dramático & v.7 (p. 102-104) \\
\cline { 2 - 3 } & Gíria & v.8 (p. 31-33) \\
& Tipo de registro & v.8 (p. 64-66) \\
\cline { 2 - 3 } & Marcadores conversacionais & v.9 (p.46-49) \\
& Preconceito na língua & (p.143) \\
\hline
\end{tabular}

Fonte: Elaborado pela autora.

Essa falta de equidade na distribuição dos assuntos relacionados à variação linguística pode levar o aluno a fazer inferências equivocadas em relação às características do processo de variabilidade na língua. Em outras palavras, estudar esse processo em um ano e não estudar em outro ou estudar mais em um ano do que no outro pode gerar a falsa impressão de que existem fases da língua em que não há 
variação. É crucial que o aluno perceba que esse processo, além de universal, é contínuo nas línguas humanas (LABOV, 1983, 1995; WEINREICH; LABOV; HERZOG, 2006 [1968]). Assim, é preciso que o professor esteja atento a questões como essa e complemente as informações, discutindo a diversidade linguística com base em outros materiais didáticos ou a partir de textos da coleção adotada que permitam esse tipo de discussão.

Quanto à dimensão em que a variação atua, os conteúdos abordados nas coleções examinadas referem-se aos seguintes tipos de variação:

(i) diatópica (por exemplo, diferenças lexicais entre as variedades brasileira e europeia do português, português ou brasileiro?, variação linguística: variedades regionais);

(ii) diamésica (por exemplo, diferenças entre fala e escrita, linguagem oral e escrita, marcas de oralidade etc);

(iii) diafásica (por exemplo, linguagem e adequação à situação discursiva, níveis de linguagem: formal e informal, tipos de registro);

(iv) diastrática (variação linguística: variedades sociais, gíria).

Ressalte-se que nem sempre o tipo de variação é explicitado mas ele pode ser inferido a partir do conteúdo e atividades propostos. A título de ilustração, no estudo de gírias (conteúdo que remete à variação social), nas atividades realizadas, são feitas associações de gírias a grupos etários e sociais, como se observa, respectivamente, em (1) e (2).

\section{(1) Gírias}

Leia as expressões destacadas nos trechos a seguir:

-Caras, vocês não sabem do que estão falando.

- Eu quero curtir ficar sozinho, me entendem?

-Disse que eu era um cara superlegal, e mais umas coisas que eu não vou ficar repetindo aqui porque fico sem jeito.

a) Que faixa etária costuma empregar expressões desse tipo?

b) Imagine se você tivesse de dizer essas frases. Provavelmente, você usaria outros termos no lugar das palavras e expressões destacadas. Como você e outros adolescentes de sua geração diriam essas frases. (OLIVEIRA et al., 2015, v.8, p. 31-32)

\section{(2) Gírias}

Que tal fazer um levantamento de outras gírias, usadas por diferentes grupos sociais? Por exemplo, esqueitistas, integrantes da cultura hip-hop, surfistas etc.

[...] (OLIVEIRA et al., 2015, v.8, p. 33) 
Ao tratar de tipos de variações a partir de livros didáticos, o professor deve perceber se há um destaque maior para um tipo ou outro e fornecer mais informações sobre o tipo negligenciado ou menos explorado. No material didático analisado, embora haja exemplos que podem ser relacionados a diferentes tipos de variação, constata-se que há uma maior incidência de tópicos referentes à variação diamésica e uma menor referência à variação diastrática.

Quanto à sistematização dos conteúdos atinentes à diversidade linguística, verificam-se ainda inadequações procedimentais na proposição de algumas atividades. A título de ilustração, em uma das coleções, começa-se a tratar do conteúdo variedade linguística a partir de uma variante estigmatizada, o uso de a gente com verbo na primeira pessoa do plural: a gente aparecemos (3).

\title{
(3) Variedade linguística
}

1. Observe a maneira como um personagem do texto expôs sua opinião e responda às próximas questões.

A senhora vem de calça comprida, e a gente aparecemos de qualquer jeito.

a) A construção destacada no trecho está de acordo com as regras gramaticais? Por quê?

b) Construções como essa em destaque podem aparecer na fala das pessoas quando elas se comunicam? Por que você acha que isso acontece? (OLIVEIRA et al., 2015, v.6, p. 74)

A variante destacada em (3) é extraída de um texto discutido em uma atividade de leitura, $\mathbf{N a}$ escola, de Carlos Drummond de Andrade. O interessante é que, nesse mesmo texto, aparece outra ocorrência não estigmatizada de a gente - a gente tem de respeitar o uniforme (OLIVEIRA et al., v.6, p. 69) - e nenhuma observação é feita sobre esse uso.

Esse tipo de procedimento acaba por reforçar preconceitos e estereótipos linguísticos e prestar um desserviço à pedagogia da variação linguística, o que se coaduna com a afirmação de Vieira (2013):

\begin{abstract}
A observação dos materiais e o depoimento de diversos professores em cursos de extensão demonstram que a relação entre ensino e variação linguística está [...] por ser repensada para o cumprimento de bons propósitos. Verifica-se, por vezes, uma visão estereotipada e dicotômica do amplo espectro da variação, que, levada às últimas consequências, pode ser ainda mais perniciosa do que aquela que sustenta o trabalho com uma só norma idealizada segundo modelos tradicionais. (VIEIRA, 2013, p. 66).
\end{abstract}

Outro procedimento inadequado tem a ver com a indução à formulação pelo aluno de falsos conceitos e correlações a partir da observação de dados, como demonstra a atividade sobre tipos de registro ilustrada em (4). O problema dessa atividade é associar a não realização do "r" final em verbos no infinitivo a contextos informais. Em relação ao português brasileiro, em diferentes comunidades de fala, essa variante não é estigmatizada e, por conseguinte, quem a usa não sofre avaliação negativa; assim, ela também ocorre em contextos formais.

\section{(4) Tipos de registro}


1. As formas "assiná" e "estudá", que aparecem no poema, correspondem aos registros formais "assinar" e "estudar", respectivamente. O que mudou no registro dessas duas palavras em relação à forma padrão? (OLIVEIRA et al., 2015, v.8, p. 64)

No que concerne a outros fenômenos variáveis do português brasileiro, algumas contradições são recorrentes. Isso é bastante evidente no estudo dos pronomes pessoais. Conforme já constatado por Carvalho e Oliveira (2016), há uma grande dificuldade de as coleções lidarem com as formas você e a gente no que diz respeito à sua categorização e/ou à sua relação com outros pronomes. Nas quatro coleções aqui analisadas, não há inclusão de você, vocês e a gente no elenco dos pronomes pessoais e ocorre a classificação de você apenas como pronome de tratamento (cf. figura 1).

Figura 1: Atividade sobre o pronome você(VASCONCELOS, 2011, v.5, p. 117)

3 Mafalda, a personagem desta tira, não gosta de sopa.
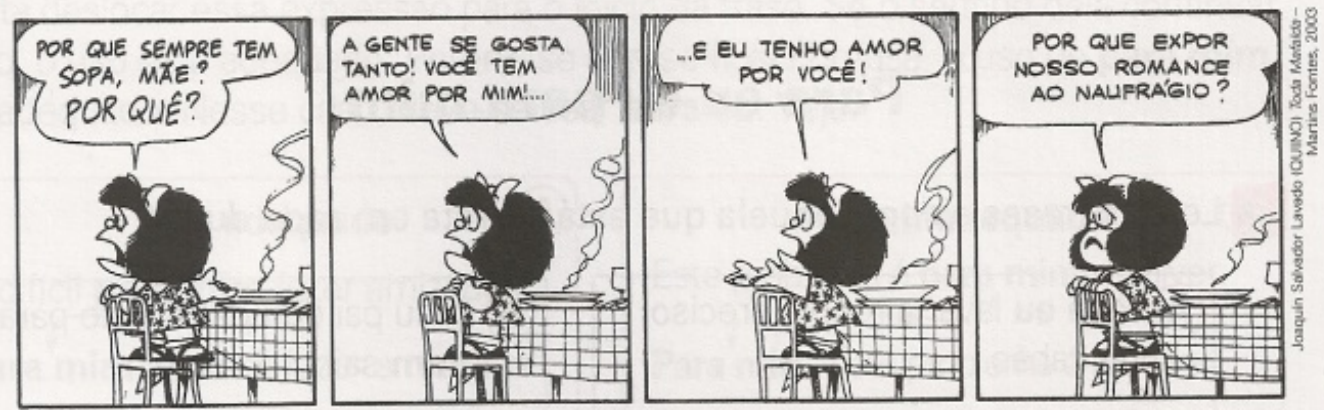

Quino. Toda Mafalda: da primeira à última tira. Sāo Paulo: Martins Fontes, 2003. p. 268.

a) Com quem Mafalda está falando? com a mãe.

b) A palavra você é um pronome de tratamento. Na tira, o uso dessa palavra demonstra distanciamento ou familiaridade entre Mafalda e a pessoa com quem ela está falando? Familiaridade.

c) Se Mafalda quisesse usar um pronome de tratamento respeitoso, qual destes seria mais adequado à situação familiar acima? Copie-o.

Vossa Alteza

Vossa Excelência

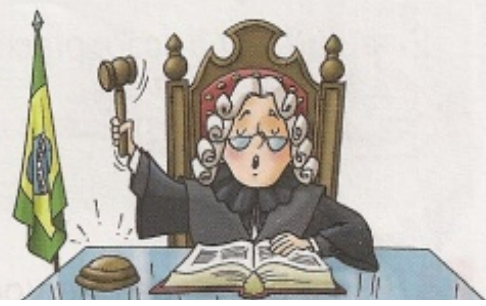

Fonte: Carvalho e Oliveira (2016, p. 50).

O interessante é que, na tira Mafalda, aparecem tanto você como a gente como pronomes pessoais. A mesma situação em relação a você é evidenciada em Costa et al. (2012), em uma atividade sobre pessoas do discurso com base na tira Snoopy (cf. figura 2) e em Oliveira et al., 2015), na introdução do conteúdo pronomes pessoal e possessivo com base em uma carta (5). 
Figura 2: Abordagem de pronomes pessoais e de tratamento e pessoas do discurso

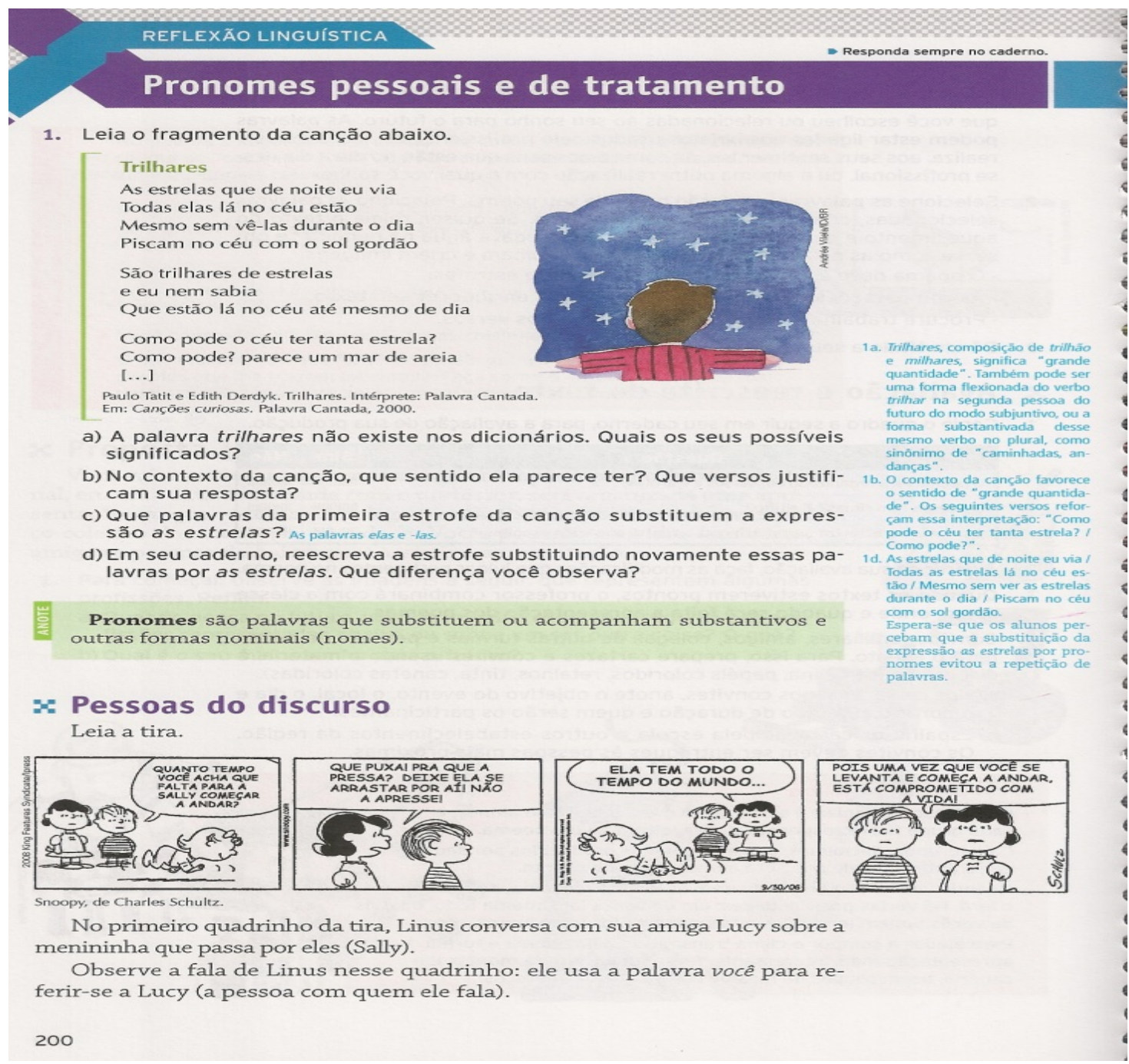

Fonte: Costa et al. (2012, v.6, p. 200).

\section{(5) Pronomes pessoal e possessivo}

1. Observe as palavras destacadas na carta da mãe de Carol. Essas palavras estão se referindo a nomes. Mas que nomes? Para responder, leia as perguntas a seguir:

$[\ldots]$

b) No texto, "você" está no lugar de que palavra? (OLIVEIRA et al., 2015, v.6, p. 119)

Contradições também estão presentes no manual do professor: em uma resposta para uma questão sobre "palavras e expressões que indicam quem está falando e as que indicam com quem se 
fala", arrolam-se, entre outras, a gente e você mas não se faz nenhuma referência ao emprego dessas formas no estudo de pronomes pessoais (COSTA et al., 2012, v.7, p. 56). Geralmente, nas coleções, constam apenas notas explicativas sobre a gente (6), você e vocês (7).

(6) A gente é uma expressão muito utilizada na linguagem informal e equivale ao pronome nós. É importante observar que o verbo que acompanha essa expressão deve ficar na terceira pessoa do singular. (COSTA et al., 2012, v.7, p. 179)

(7) Na linguagem oral, a maioria dos brasileiros usa a expressão a gente no lugar de nós. Nas frases com essa expressão, o verbo deve ficar no singular. Exemplo: Nós estamos felizes A gente está feliz. (VASCONCELOS, 2011, v.4, p. 185, at. 4)

(8) No Brasil, é comum o uso do pronome você no lugar do pronome tu e de vocês no lugar de vós. (VASCONCELOS, 2011, v.5, p. 116)

Observe-se que, pela explicação em (6), (7) e (8), fica claro que a gente e nós, de um lado, e você e tu, do outro, estão em variação; portanto, esses pronomes deveriam ser descritos, no quadro pronominal, como formas variantes, mas isso não acontece. Ademais, existe uma tendência de se referir a a gente apenas como uma expressão sem nenhum tipo de categorização, como em (6), (7). Ainda em (8), considera-se, equivocadamente, que vocês varia com vós. Sabe-se que, no português brasileiro, o emprego de vós praticamente inexiste, restringindo-se a um contexto bem específico de uso da língua, aquele ligado à esfera religiosa. Sobre a relação entre ensino e variação entre alguns dos pronomes supracitados, Vianna e Lopes (2015) afirmam que:

\begin{abstract}
Mesmo que no ensino o pronome "nós" continue sendo apresentado como o legítimo pronome de primeira pessoa do plural, a forma "a gente" não sofre uma avaliação negativa da comunidade e, por isso, já vem aparecendo com frequência em textos escritos [...]. O fato de o pronome "nós" ser ainda ensinado na escola não constitui um freio para a mudança, porque o arcaizante pronome "vós" também aparece no quadro pronominal da gramática tradicional e nos manuais didáticos, embora já seja ponto pacífico que a sua substituição por "vocês" está completamente implementada no Brasil e, até mesmo, em Portugal. (VIANNA; LOPES, 2015, p. 130)
\end{abstract}

A referência, apenas em notas, às formas pronominais você, vocês e a gente revela falta de atualização de conceitos em relação não só à identificação dos membros da classe dos pronomes pessoais, mas também, como mencionado em Carvalho e Oliveira (2016, p. 52), "à mudança no paradigma pronominal do português brasileiro [...] que, de forma diferente do que se propõe em diversos livros didáticos de português, aponta para uma configuração bastante diversa do paradigma do português europeu $[\ldots]^{\prime \prime}$.

Usos reais do português também são ignorados na abordagem dos pronomes demonstrativos, mais especificamente, no que concerne à variação entre este(a)(s) e esse(a)(s) (CARVALHO; OLIVEIRA, 2016): em uma coleção (VASCONCELOS, 2011), trata-se como inadequado o emprego de essa para se referir a algo que está próximo de quem fala (cf. figura 3); em outra coleção (COSTA et al., 2012), no material multimídia (DVD, categoria audiovisual), faz-se, com base em uma situação de feira, a distinção entre os pronomes esta e aquelas, usados, nessa situação, respectivamente, para referência às 
frutas mais próximas e mais distantes da pessoa que está falando; no entanto, no início do audiovisual, apresenta-se como exemplo uma situação em que um feirante utiliza esse para fazer remissão a um pacote que está nas mãos dele (9).

Figura 3: Abordagem de pronomes demonstrativos

Os pronomes demonstrativos indicam uma posição no espaço ou no tempo.

\begin{tabular}{|l|l|}
\hline \multicolumn{1}{|c|}{$\begin{array}{c}\text { Pronomes } \\
\text { demonstrativos }\end{array}$} & Situação de uso \\
\hline este(s), esta(s), isto & Indicam o que está perto de quem fala. \\
\hline esse(s), essa(s), isso & Indicam o que está próximo da pessoa com quem se fala. \\
\hline aquele(s), aquela(s), aquilo & Indicam algo distante de quem fala e da pessoa com quem se fala. \\
\hline
\end{tabular}

4 Observe e leia esta tira. Depois, responda ao que se pede com base nas informações do quadro acima. 4b Não. Pela proximidade da pessoa que fala em relação ao elemen

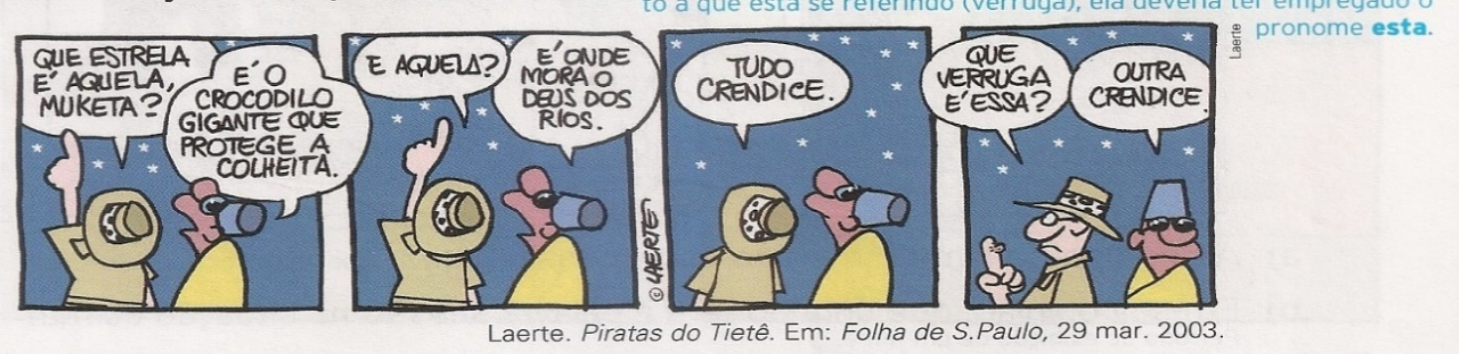

a) Por que a personagem usa o pronome demonstrativo aquela para se referir às estrelas? Porque elas estão distantes de onde a personagem se encontra.

b) No último quadrinho, o emprego do pronome essa está adequado?

c) A que crendice a personagem se refere no último quadrinho? Explique. Resposta pessoal. Comente com os alunos que há uma crendice popular segundo a qual contar ou apontar estrelas faz nascer verrruga no dedo usado.

Fonte: Vasconcelos (2011, v.5, p. 135, at. 4b).

(9) Esse pacote é três reais com quatro. (COSTA et al., 2012, v.,6 Audiovisual).

Mais uma vez, o professor de língua materna precisa perceber inconsistências teóricometodológicas como as constatadas nas atividades sobre pronomes demonstrativos e, pautado em outras situações de usos reais do português, explicar e demonstrar aos alunos que a variação entre este(a)(s) e esse(a)(s) é bastante comum na variedade brasileira dessa língua e não é estigmatizada.

Em síntese, para ter um posicionamento crítico em relação ao material adotado em sala de aula, às suas imprecisões e inadequações, segundo Dionísio (2002, p. 85), "na relação com o livro didático, o professor deverá sempre ser superior a ele em conhecimento e em desempenho metodológico". Essa criticidade do docente deve começar a ser construída durante a sua formação acadêmica e deve continuar no exercício do magistério. 


\section{Considerações finais}

Neste trabalho, a partir do exame de coleções do quarto e quinto anos e do sexto ao nono ano e dos resultados de Carvalho (2012) e Carvalho e Oliveira (2016), debruçou-se sobre o tratamento da variação linguística no livro didático de português, com ênfase em imprecisões conceituais e inadequações procedimentais referentes a esse tratamento.

De modo geral, constata-se que, de forma a cumprirem um dos critérios do PNLD específicos para língua portuguesa e não serem excluídas durante o processo de avaliação, todas as coleções analisadas fazem referência explícita à diversidade linguística através de sistematização de conteúdos e/ou proposição de atividades. No entanto, o que se observa é que tal referência não é uma constante em todos os volumes de algumas coleções ou há uma discrepância na abordagem dos conteúdos de um ano para o outro. Assim, parece que a preocupação dos autores dos livros didáticos é a de apenas mencionar, em algum volume das suas obras, a variação linguística e, por conseguinte, atender à exigência do PNLD.

Ademais, embora haja uma análise criteriosa dos avaliadores do PNLD, ainda permanecem coleções que apresentam inconsistências teórico-metodológicas. Carvalho (2012) e Carvalho e Oliveira (2016) demonstraram essas inconsistências em relação à variação linguística e a classes de palavras (substantivos, adjetivos, pronomes e verbos), respectivamente. No material aqui analisado, também se evidenciam imprecisões conceituais e inadequações procedimentais concernentes à discussão do processo de variação linguística. Ratificando resultados de Carvalho (2012), a sistematização dos conteúdos referentes a esse processo revela, além de uma distribuição assimétrica desses conteúdos nos volumes da coleção, as seguintes questões que precisam ser redimensionadas: (a) indução à formulação pelo aluno de falsos conceitos e correlações a partir da observação de dados; (b) presença de atividades que manifestam preconceito e/ou estereótipo linguísticos; (c) contradição no tratamento de fenômenos variáveis do português brasileiro. Além dessas, verificam-se ainda a abordagem da variação linguística a partir de variantes estigmatizadas e, quando se comparam os tópicos sobre variação linguística nas quatro coleções, a ocorrência de mais conteúdos referentes a um tipo de variação (no caso, a diamésica).

Algumas das questões supracitadas têm sido recorrentes em livros didáticos de português analisados em diferentes anos do PNLD, o que serve como evidência de que os autores desses livros ainda estão, de fato, buscando o caminho adequado ou "acertando o passo" (DIONísIO, 2002) para lidarem com aspectos atinentes à variação linguística.

O professor de português tem que partir do pressuposto de que não existe material didático ideal e desconfiar, no bom sentido, do livro adotado. Mas ele só consegue desconfiar no sentido de identificar, questionar e rever inconsistências teórico-metodológicas se ele tiver uma boa formação (socio)linguística e mobilizar os seus conhecimentos (socio)linguísticos em sala de aula. Nessa mesma direção, tomam-se aqui emprestadas as palavras de Martins, Vieira e Tavares (2014, p. 34) duas vezes: primeiro, para enfatizar que "o conhecimento científico e a prática pedagógica precisam estar mais próximos e caminhar juntos, para que sejam alcançados os objetivos postulados para o ensino de português no país [...]"; segundo, para se acentuar a importância de "conhecer profundamente as práticas escolares, os materiais didáticos adotados [...], para que se possa investir na elaboração de propostas pedagógicas, que configurem práticas sociolinguísticas fundamentadas". Em suma, assume-se, com Carvalho e Oliveira (2016), que, 
para o professor lidar com inconsistências teórico-metodológicas de materiais didáticos, devem sobressair e interagir, na sua práxis, a sua formação e a sua função de mediador de conhecimentos.

\section{Referências}

BAGNO, M. Nada na língua é por acaso: por uma pedagogia da variação linguística. São Paulo: Parábola, 2007. $238 \mathrm{p}$.

BAGNO, M. Variação, avaliação e mídia: o caso do ENEM. In: ZILLES, A. M. S.; FARACO, C. A. (orgs.) Pedagogia da variação linguística. São Paulo: Parábola, 2015. 320 p

BAGNO, M.; RANGEL, E. de O. Tarefas da educação linguística no Brasil. Revista Brasileira de Linguística Aplicada, Belo Horizonte, v. 5, n. 1, p. 63-81, 2005.

BORTONI-RICARDO, S. M. Educação em língua materna: a sociolinguística na sala de aula. São Paulo: Parábola, 2004. 108 p.

BORTONI-RICARDO, S. M. Nós cheguemu na escola, e agora? sociolinguística e educação. São Paulo: Parábola: 2005. 263 p.

BRIGHT, W. As dimensões da Sociolinguística. In: FONSECA, M. S. V.; NEVES, M. Facure (orgs.), Sociolinguística. Rio de Janeiro: Eldorado, 1974.

CAFIERO, D. Letramento e leitura: formando leitores críticos. In: RANGEL, E. O.; ROJO, R. H. R. (coords.). Língua Portuguesa: ensino fundamental. Brasília: Ministério da Educação, Secretaria de Educação Básica, 2010. p. 85-106. (Coleção Explorando o Ensino. v. 19).

CARVALHO, C. S. Variação linguística no livro didático de português: o que mudou com o PNLD? In: Diversidade linguística e políticas de ensino: Anais / II Congresso Internacional de Dialetologia e Sociolinguística. São Luís: EDUFMA, 2012. p. 1146-1157. Disponível em: http://www.youblisher.com/p/540229-ANAIS-II-CIDS-2012/ Acesso em: 04 mar. 2018.

CARVALHO, C. S.; OLIVEIRA, I. O. Abordagem de classes de palavras no livro didático: contribuições da linguística para um ensino produtivo de língua portuguesa. In: Encontro Nacional de Ensino e Linguagem: Pensando o Ensino de Língua e de Literatura na Atualidade. 2016, São Luís. Anais. São Luís: EDUFMA, 2016. p. 39-57.

COSTA, C. L. et al. Para Viver Juntos Português. 3. ed. São Paulo: SM, 2012. v. 6-9.

CYRANKA, L. F. Mendonça. A pedagogia da variação linguística é possível? In: ZILLES, A. M. S.; FARACO, C. A. (orgs.) Pedagogia da variação linguística. São Paulo: Parábola, 2015. 320 p

DIONISIO, A. P. Variedades linguísticas: avanços e entraves. In: DIONÍSIO, A. P.; BEZERRA, M. A. (orgs.). $O$ livro didático de português: múltiplos olhares. Rio de Janeiro: Lucerna, 2002. p. 75-88.

LABOV, W. Modelos sociolinguísticos. Madrid: Cátedra, 1983.

Principles of linguistic change: internal factors. v. 1. Cambridge: Blackwell, 1995.

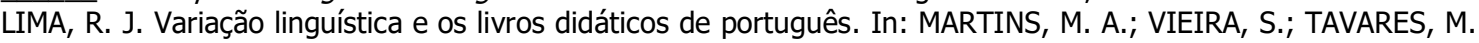
A. Ensino de português e sociolinguística. São Paulo: Contexto, 2014. p. 115-131.

MARTINS, M. A.; VIEIRA, S.; TAVARES, M. A.Contribuições da sociolinguística brasileira para o ensino de português. In: MARTINS, M. A.; VIEIRA, S.; TAVARES, M. A. Ensino de português e sociolinguística. São Paulo: Contexto, 2014. p. 9-35.

OLIVEIRA, T. A. et al. Tecendo linguagens - língua portuguesa. 4. ed. São Paulo: IBEP. 2015. v.6-9

VASCONCELOS, A. Aprender juntos - Língua Portuguesa. 3. ed. São Paulo : SM, 2011. v. 4-5.

VAZ, D.; MORAES, E. N.; VELIAGO, R.. Português, Escrita, Leitura e Oralidade. São Paulo : Moderna, 2011. v. 4-5.

VIEIRA, M. G.; FIGUEIREDO, R. Ler, entender, criar. Língua Portuguesa. São Paulo: Ática, 2007, v.6-9.

VIANNA, J. S.; LOPES, C. R. S. Variação dos pronomes "nós" e "a gente". In: MARTINS, M. A.; ABRAÇADO, J.. (orgs.) Mapeamento sociolinguístico do português brasileiro. São Paulo: Contexto, 2015. p. 109-131.

VIEIRA, S. Sociolinguística e ensino de português: para uma pedagogia da variação linguística. In: MARTINS, M. A.; TAVARES, M. A. (orgs.). Contribuições da sociolinguística e da linguística histórica para o ensino de língua portuguesa. Natal: EDUFRN, 2013. p. 55-90. (Coleção ciências da linguagem aplicadas ao ensino, v. 5).

WEINREICH, U.; LABOV, W.; HERZOG, M. I. Fundamentos empíricos para uma teoria da mudança. São Paulo: Parábola, 2006. Trad. de Marcos Bagno.

ZILLES, A. M. S.; FARACO, C. A. (orgs.) Pedagogia da variação linguística. São Paulo: Parábola, 2015. 320 p. 